\title{
Efficacy and Safety of Dabigatran for the Treatment and Clinical Resolution of a Case of Spermatic Vein Thrombosis
}

\section{Di Micco Pierpaolo*}

Department of Medicine, Fatebenefratelli Hospital of Naples, Italy

\begin{abstract}
Spermatic vein thrombosis is a rare case of testicular pain. An early diagnosis of spermatic vein thrombosis is very difficult to perform and for this reason the clinical approach is usually surgery with associated frequent worsening of fertility. Here we report a case of spermatic vein thrombosis with an early diagnosis and early antithrombotic treatment with enoxaparin twice daily and thereafter with full dose dabigatran twice daily.
\end{abstract}

Keywords: Dabigatran; Direct oral anticoagulants; DOACs; Spermatic vein thrombosis; Varicocele

Abbreviations: aPTT: Activated Partial Thromboplastin Time; INR: International Normalized Ratio; LAC: Lupus Anticoagulant; PICC-DVT: Peripherally Inserted Central Catheter-Related Deep Vein Thrombosis; PT: Prothrombin Time

\section{Introduction}

Acute testicular pain is frequent in urology. It may be a result of a twisted spermatic cord, twisted testicular appendages or epididymitis [1]. It also occurs due to testicular trauma, orchitis, idiopathic scrotal oedema, or testicular neoplasm [1]. Rarely, acute painful scrotum may be associated with thrombosis of the internal spermatic vein or pampiniform plexus veins [1] and is an unexpected finding in the differential diagnosis of acutely painful scrotum [2]. If torsion of the spermatic cord and orchiepididymitis are normal, thrombosis of the pampiniform plexus is very uncommon. Spermatic vein thrombosis, in fact, is a rare event and requires careful examination for the differential diagnosis. Most cases of spermatic vein thrombosis involve the left side [3] and clinical presentation usually includes left acute testicular pain and testicular swelling in both children and adults [4].

We report a case of spermatic vein thrombosis resolved with early diagnosis and antithrombotic treatment without a surgical approach and sequelae on testicular function.

\section{Case Report}

A 29-year-old man was referred to the emergency department for spontaneous and non-traumatic pain to the right scrotum. His personal and pharmacological history was unremarkable. Physical examination revealed light swelling of the scrotum, not associated with haematoma or fever; yet the scrotum was also firm, erythematous, and tender, and these characteristics did not change when standing, supine, or with Valsalva manoeuver. Pain was not relieved after NSAIDs injection. Ultrasound did not find a testicular lesion, but a vascular scan revealed grade II varicocele without blood flow to Doppler scan as sign of a recent partial thrombosis of vena testis. An extension of the Doppler scan found an acute thrombus in the right gonadal vein (Figure 1) which was confirmed by CT scan. Analgesia treatment was started with IV ketorolac and morphine $3 \mathrm{mg}$ in combination with enoxaparin 40 $\mathrm{mg}$ twice daily. Antibiotics were also administered (i.e. ceftriaxone 2 $\mathrm{g}$ daily and ofloxacin $400 \mathrm{mg}$ daily) due to the frequent evolution to surgery of vascular thrombosis of varicocele.

The patient's clinical features improved, and the pain progressively reduced in intensity as did local edema and erythema, so the current treatment was continued. A thorough screening ruled out inherited or acquired thrombophilia (Table 1).
Because of the progressive improvement without clinical complications such as fever, infection and local edema, an extension of antithrombotic therapy was planned with antivitamin $\mathrm{K}$ antagonists such as warfarin. Yet, because of the relevant number of drug-drug and food-drug interactions, and frequent laboratory monitoring of extended warfarin treatment, the patient rejected this proposal and prolonged injections of enoxaparin. So, although indicated for the treatment of venous thromboembolism (VTE) in lower limb deep vein thrombosis with or without pulmonary embolism (PE), extended antithrombotic treatment with direct oral anticoagulants (DOACs) was considered. Because of the relevant efficacy and safety at full doses for the treatment of VTE, dabigatran was chosen. Dabigatran $150 \mathrm{mg}$ twice daily was initiated with good clinical tolerance.

After three months of treatment with dabigatran, no biochemical abnormalities, local clinical abnormalities such as edema or pain, or abnormalities of fertility spectrum were detected. Moreover, a further ultrasound scan of the testicular gland was performed with vascular

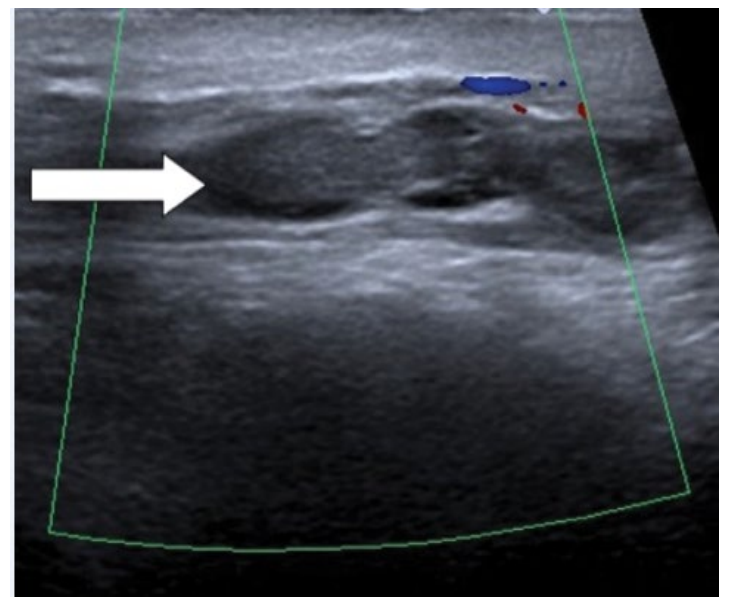

Figure 1: Doppler scan: Acute thrombus in the right gonadal vein.

*Corresponding author: Di Micco Pierpaolo, Department of Medicine, Fatebenefratelli Hospital of Naples, Italy, Tel: 00393398078146; E-mail: pdimicco@libero.it

Received November 06, 2018; Accepted November 10, 2018; Published November 12, 2018

Citation: Di Micco Pierpaolo (2018) Efficacy and Safety of Dabigatran for the Treatment and Clinical Resolution of a Case of Spermatic Vein Thrombosis. J Clin Case Rep 8: 1188. doi: 10.4172/2165-7920.10001188

Copyright: $\odot 2018$ Di Micco Pierpaolo. This is an open-access article distributed under the terms of the Creative Commons Attribution License, which permits unrestricted use, distribution, and reproduction in any medium, provided the original author and source are credited. 
Citation: Di Micco Pierpaolo (2018) Efficacy and Safety of Dabigatran for the Treatment and Clinical Resolution of a Case of Spermatic Vein Thrombosis. J Clin Case Rep 8: 1188. doi: 10.4172/2165-7920.10001188

\begin{tabular}{|c|c|c|}
\hline Test & Normal value & Patient's value \\
\hline Red blood cells $\left(\mathrm{mm}^{3}\right)$ & $3,000,000-5,000,000$ & $3,500,000$ \\
\hline Hemoglobin $(\mathrm{g} / \mathrm{dl})$ & $11-15$ & 13.0 \\
\hline White blood cells $\left(\mathrm{mm}^{3}\right)$ & $4000-10000$ & 12,300 \\
\hline Platelets $\left(\mathrm{mm}^{3}\right)$ & $1,00,000-4,00,000$ & $2,81,000$ \\
\hline PT INR & $0.8-1.2$ & 0.9 \\
\hline aPTT (sec) & $23-38$ & 33 \\
\hline Fibrinogen $(\mathrm{mg} / \mathrm{dl})$ & $200-400$ & 243 \\
\hline d-Dimer $(\mu \mathrm{g} / \mathrm{dl})$ & $<500$ & 675 \\
\hline MTHFR c677t gene variants & Genotype CC & Genotype CC \\
\hline PTHRA201210G gene variant & Genotype AA & Genotype AA \\
\hline Factor V Leiden gene variant & Genotype AA & Genotype AA \\
\hline Protein S (\%) & $60-120$ & 72 \\
\hline Protein C $(\%)$ & $60-120$ & 84 \\
\hline AT III (\%) & $80-120$ & 96 \\
\hline LAC & Absent & Absent \\
\hline IgG anticardiolipin (U/GPL) & $<20$ & $<20$ \\
\hline IgM anticardiolipin (U/MPL) & $<20$ & $<20$ \\
\hline
\end{tabular}

Table 1: Laboratory tests of patient with spermatic vein thrombosis.

recanalization of the previous thrombosis but with a worsening of varicocele.

\section{Discussion}

The diagnosis of spermatic vein thrombosis is very difficult and rare, and surgery is frequently considered [5] with the worsening of fertility. Moreover, advice on the best antithrombotic treatment for this type of VTE is not available in current international guidelines.

Our experience showed that an early diagnosis of spermatic vein thrombosis and early antithrombotic treatment may have a benefit not only on local evolution and escaping the surgical approach but also on fertility spectrum.

Other cases reported in the literature were all based on extended treatments with low molecular weight heparins or warfarin $[1,6]$. To the best of our knowledge, this is the first case of spermatic vein thrombosis treated with a DOAC. Dabigatran has similar effects on VTE recurrence and a lower risk of bleeding compared with warfarin for the treatment of acute VTE [7-9].

Real world experience shows that DOACs are sometimes used off label for the treatment of VTE in unusual sites as in the case we reported.
The treatment we chose resulted in the full resolution of spermatic vein thrombosis symptoms, avoidance of surgery and no worsening of fertility; furthermore, the treatment had a good safety profile with no bleeding complications or side effects. It is important to specify that this was an off-label study, and that, despite contributing to the expansion of both scientific and clinical knowledge, an appropriate prescription according to the approved clinical indications is mandatory and crucial.

\section{Conclusion}

In conclusion, although spermatic vein thrombosis remains very rare, we suggest this therapeutic option be considered and plan a dedicated study in order to better understand the benefit of dabigatran in this clinical setting.

\section{Acknowledgment}

Editorial assistance was provided by Carmen Innes on behalf of Springer Healthcare with the support of Boehringer Ingelheim.

\section{References}

1. Kamel K, Gassen S, Mohamed M (2018) Bilateral spontaneous thrombosis of the pampiniform plexus: A rare etiology of acute scrotal pain: A case report and review of literature. Afr J Urol 24: 14-18.

2. Kleinclauss F, Negra ED, Martin M, Bernardini S, Bittard H (2001) Spontaneous thrombosis of left varicocele. Prog Urol 11: 95-96.

3. Hashimoto L, Vibeto B (2006) Spontaneous thrombosis of the pampiniform plexus. Scand J Urol Nephrol 40: 252-254.

4. Castillo OA, Diaz M, Vitagliano GJ, Metrebian E (2008) Pulmonary thromboembolizm secondary to left spermatic vein thrombosis: A case report. Urol Int 80: 217-218.

5. Campagnola S, Flessati P, Fasoli L, Sulpasso M, Pea M (1999) A rare case of acute scrotum: Thrombophlebitis from ectasia of the left pampiniforme plexus. Minerva Urol Nephrol 51: 163-165.

6. Bolat D, Gunlusoy B, Yarimoglu S, Ozsinan F, Solmaz S (2016) Isolated thrombosis of right spermatic vein with underlying Factor $V$ Leiden mutation. Can Urol Assoc J 10: 324-327.

7. Schulman S, Kearon C, Kakkar AK, Mismetti P, Schellong S, et al. (2009) Dabigatran versus warfarin in the treatment of acute venous thromboembolism. N Engl J Med 361: 2342-2352.

8. Schulman S, Kearon C, Kakkar AK, Schellong S, Eriksson H, et al. (2013) Extended use of dabigatran, warfarin, or placebo in venous thromboembolism. N Engl J Med 368: 709-718.

9. Schulman S, Kakkar AK, Goldhaber SZ, Schellong S, Eriksson H, et al. (2014) Treatment of acute venous thromboembolism with dabigatran or warfarin and pooled analysis. Circulation 129: 764-772. 